\title{
Local heat transfer in subcooled flow boiling in a vertical mini-gap
}

\section{channel}

\author{
Wei $\mathrm{Li}^{1^{*}}$, Junye $\mathrm{Li}^{1,4}$, Zhaozan Feng ${ }^{2 *}$, Kan Zhou ${ }^{1}$, Zan $\mathrm{Wu}^{3}$
}

1. Department of Energy Engineering, Zhejiang University, Hangzhou, 30027, Zhejiang, China

2. CRRC Zhuzhou Electric Locomotive Institute Co., Ltd., Zhuzhou 412000, Hunan, China

3. Department of Energy Sciences, Faculty of Engineering, Lund University, P.O. Box 118, SE22100 Lund, Sweden

4. Department of Energy Engineering, Collaborative Innovation Center of Advanced AeroEngine, Zhejiang University, Hangzhou, 310027, China

* Corresponding author 1. Tel./fax: +86 57187952244. E-mail addresses: weili96@zju.edu.cn (W. Li).

* Corresponding author 2. Tel./fax: +86 17716787484. E-mail addresses: fengzz@csrzic.com (Z. Feng).

\begin{abstract}
An experimental study of subcooled flow boiling in a high-aspect-ratio, one-sided heating rectangular mini-gap channel was conducted using deionized water. The local heat transfer coefficient, onset of nucleate boiling (ONB), and flow pattern of subcooled boiling were investigated. The influence of heat flux and mass flux were studied with the aid of a high-speed camera. The bubbles were generated more quickly at higher heat flux and the diameters of departing bubbles decreased with increased flow mass flux. Partial dry-out and rewetting process caused by elongated bubble was also observed at lower mass flux. With the increase of heat flux, the surface near exit started boiling firstly, with more sharply increased heat transfer coefficient compared to the surface near entrance. The experimental heat transfer coefficients were analyzed using four existing
\end{abstract}


correlations. The four correlations are all in an error band of $-20 \%$ to $+25 \%$, and Chen correlation tends to have better performance at higher heat transfer coefficient.

Keywords: Subcooled flow boiling; Heat transfer; onset of nucleate boiling; Mini-gap channel.

\section{Introduction}

Highly efficient heat-dissipation system is of great importance to the operation, duration, and performance of high power components such as IGBT (Insulated-Gate Bipolar Transistor) chips. The conventional air cooled and water cooled heat exchangers are unable to meet the need of high heat-flux dissipation density due to the increased power consumption and decreased size of these devices [1]. Tuckerman and Pease found that the microchannel heat sink was a very promising solution for highly efficient heat dissipation in 1981 [2]. Higher heat transfer coefficient, better uniformity of temperature distribution, and lower mass flux as well as lower pump power required can be realized by utilizing phase change in the evaporators. Meanwhile, there is a variety of complicated problems in the microchannel, such as the instability of flow boiling, which imposes limitations on the application of two phase heat transfer in microchannels.

A comprehensive review about the research progress of the microchannel in recent two decades was given by Kandlikar [3]. He concluded that there is no distinct difference between the single-phase heat transfer in the microchannel and that in the classic macroscale channel. The divergences in the literature mainly existed in the two phase flow boiling. The bubbles generated by liquid boiling are confined in microchannels when the channel size is too small, which gives distinctly difference in the flow patterns, heat transfer, pressure drop, instability and critical heat flux compared with 
the macroscale channels. An author in this study [4, 5] studied the heat transfer characteristics of evaporation in micro/mini-channels and presented a criterion, $\mathrm{Bo}^{*} \mathrm{Re}_{\mathrm{l}}^{0.5}=200$ and $\mathrm{Bo}=4$ to define microscale flow boiling and macroscale flow boiling. This study's $\mathrm{Bo}^{*} \mathrm{Re}_{1}{ }^{0.5}<200$ and $\mathrm{Bo}<4$ which is in microscale flow boiling region. Based on the criterion, correlations on pressure drop, heat transfer, and critical heat flux were developed [6-10] and adopted in Two-Phase Flow, Chapter 5 of "2012-2016 ASHRAE Handbook - Fundamentals".

There have been many experimental studies for the flow boiling in parallel microchannels, whose primary drawbacks are the flow instability and relatively high pressure drop. The bubbles generated in the narrow microchannel can expand in both axial and crosswise direction in the growth period compared to the parallel microchannels, which greatly improves the flow instability and reduces pressure drop penalties [11-13].

Meanwhile, the vast majority of the micro-channels studied in previous researches were geometries like circular tubes, trapezoidal, square and low aspect ratio rectangular micro-channels. Investigations concerning micro-gaps or micro-channels with high aspect ratio have been very scarce. Closer attention to flow boiling in high aspect ratio micro-channels or micro-gaps should be paid in light of the potential of larger heat transfer surface and moderate pressure drop penalty.

In the work of Tamanna et al. [14], experiments were conducted to investigate the effects of mass flux and heat flux on flow boiling heat transfer performance and pressure drop characteristics in a silicon based micro-gap heat sink of different gap depths, $190 \mu \mathrm{m}, 285 \mu \mathrm{m}$ and $381 \mu \mathrm{m}$, using deionized water as the working fluid. The results 
indicated that higher heat transfer coefficient was achieved for micro-gap of smaller size and once the nucleate boiling began, confined slug and annular boiling dominated the heat transfer mechanisms in the micro-gap channel. For high heat fluxes, thin film evaporation occurred throughout the liquid-vapor interface which enhanced local heat transfer coefficients significantly due to confined annular flow.

In the work of Wang et al. $[15,16]$, flow boiling heat transfer characteristics in rectangular microchannels with high width-to-depth aspect ratios of 10 or 20 were experimentally investigated using FC-72 and ethanol as the working fluids. Flow pattern visualizations and thermography measurements were conducted with channel hydraulic diameters of $571 \mu \mathrm{m}, 762 \mu \mathrm{m}$ and $1454 \mu \mathrm{m}$. Flow regimes comprised of onset of nucleation boiling, confined bubbly flow which rapidly developed to slug-annular flow followed by annular flow and wispy-annular flow accompanied with cyclical flow reversal and rewetting process were successively observed and analyzed for FC-72 and then extended to ethanol.

In the present study, experimental measurements and visualizations were carried out for the onset of nucleate boiling (ONB) and local heat transfer coefficient of subcooled flow boiling in the narrow mini-gap channel with deionized water as the working fluid.

\section{Experimental method}

\subsection{Experimental apparatus}

Fig. 1 shows the schematic of the flow boiling experimental setup. Before the boiling test, deionized water was fully degassed by long-time boiling. At the end of degassing, dissolved oxygen (DO) content within the water was measured using a DO 
sensor (Mettler Toledo InPro 6850i/12/120). The measured DO content was $3.7 \mathrm{ppm}$ at $34{ }^{\circ} \mathrm{C}$. The deionized and degassed water flowed through the gear pump, filters, mass flow meter, high temperature water bath, electrical heating section and the test section. Finally, the water flowed into the plate heat exchanger where it was cooled and flowed back to the storage tank.

The inlet and outlet fluid temperatures were measured by the $0.3 \mathrm{~mm}$ T-type thermocouple and $1 \mathrm{~mm}$ outer-diameter K-type thermocouple, respectively. The wall temperature sensors of the test section were fabricated by soldering $0.254 \mathrm{~mm}$ T-type thermocouples. All thermocouples were calibrated using a constant temperature water bath. The gauge pressure at the entrance of the test section was measured by a pressure transmitter and the differential pressure in the test section was measured by a differential pressure transmitter. All the relevant parameters were recorded by Agilent 34970A at 5 second intervals. Models of the components are listed in Table 1.

The narrow mini-gap channel test section is the core of the experimental setup. It is composed of four main components: (1) top cover made of PSU(Polysulfone), above which a microgroove with $80 \mathrm{~mm}$ length and $0.52 \mathrm{~mm} \times 5.01 \mathrm{~mm}$ section area is machined, as shown in Figure 2(a), (2) bottom base made of PSU, with the entrance and exit mixing columns, guide holes of the pressure, and the groove of $15 \times 30 \times 8 \mathrm{~mm}^{3}$, (3) PEEK(Polyetheretherketone) holder integrated with temperature sensors and copper electrodes, (4) flat silicon heater. The heater mainly consists of a 0.02 mm-thick Ruthenium oxide serpentine heater, a 0.4 mm-thick AlN (Aluminium nitride) wafer and a $0.5 \mathrm{~mm}$-thick silicon wafer. The resistance of the serpentine heater is about $100 \mathrm{ohms}$ at room temperature. The AlN wafer is used to electrically insulate the silicon wafer. The 
Ruthenium oxide serpentine heater was printed on AlN wafer surface by the method of printed circuit. To minimize the thermal resistance between the AlN wafer and silicon wafer, a $0.05 \mathrm{~mm}$-thick indium foil $\left(81.6 \mathrm{~W} /(\mathrm{mK})\right.$, melting point $\left.156^{\circ} \mathrm{C}\right)$ was utilized. The combination was put in an oven at $170{ }^{\circ} \mathrm{C}$ for 30 minutes, during which the components stuck together tightly and indium foil's thickness reduced to $0.01 \mathrm{~mm}$ due to melting and resolidification. The top cover and the bottom base, the flat silicon heater, and the schematic of narrow channel and the test section are shown in Fig. 2, Fig. 3, Fig. 4, respectively.

\subsection{Surface characteristics}

The silicon wafer used in the subcooled flow boiling experiments was processed by PECVD (Plasma Enhanced Chemical Vapor Deposition), and its surface was covered with one layer of $1 \mu \mathrm{m}$-thick silicon dioxide thin film, which is shown in Fig. 5(a). As shown in Fig. 5(b), the silicon dioxide surface was very smooth with the mean roughness of $0.803 \mathrm{~nm}$ measured by AFM (Atomic Force Microscope). The static contact angle of the surface was measured by the OCA20, DataPhysics Instruments GmbH. As showed in Fig. 5(c), the static contact angle of the silicon dioxide thin film's surface is about $50 \pm$ $3^{\circ}$.

\subsection{Experimental conditions}

The cross section of the mini-gap channel is $0.52 \mathrm{~mm} \times 5.01 \mathrm{~mm}$ and the hydraulic diameter is $0.94 \mathrm{~mm}$. The experimental mass fluxes ranged from $200 \mathrm{~kg} /\left(\mathrm{m}^{2} \mathrm{~s}\right)$ to $400 \mathrm{~kg} /\left(\mathrm{m}^{2} \mathrm{~s}\right)$, the heat flux ranged from $20 \mathrm{~kW} / \mathrm{m}^{2}$ to $300 \mathrm{~kW} / \mathrm{m}^{2}$, liquid subcooling at the entrance was $10{ }^{\circ} \mathrm{C}$, and the entrance gauge pressure was $10 \mathrm{kPa}$. The wall 
temperature was kept below $130{ }^{\circ} \mathrm{C}$ to protect the test section. The Phantom high speed camera worked at 1000 fps to visualize the flow patterns of the subcooled flow boiling.

\subsection{Data reduction}

Uniform axial heat flux and uniform circumferential wall temperature were assumed as the thermal boundary conditions of the test section. The bottom wall was heated while the other three sides were adiabatic. The heater temperatures were measured at six axial positions, $2.5,7.5,12.5,17.5,22.5$ and $27.5 \mathrm{~mm}$ from the entrance along the flow direction, using six T-type thermocouples. The silicon wafer wall temperatures were calculated through one-dimension heat conduction and the bulk fluid temperatures were given by linear interpolation of the inlet and outlet bulk temperatures.

For the subcooled flow boiling heat transfer, the effective heat exchange rate between the silicon wafer surface and the fluid can be expressed as:

$$
Q_{\text {eff }}=m c_{\mathrm{p}}\left(T_{\text {out }}-T_{\text {in }}\right)
$$

where $Q_{\text {eff }}, m, c_{\mathrm{p}}, T_{\text {out }}, T_{\text {in }}$ are effective heat exchange rate, mass flow rate, the specific heat, outlet temperature and inlet temperature, respectively.

The heat loss of the test section can be calculated as:

$$
Q_{\mathrm{loss}}=U \times I-m c_{\mathrm{p}}\left(T_{\mathrm{out}}-T_{\mathrm{in}}\right)
$$

where $Q_{\text {loss, }} U$ and $I$ are the heat loss rate, the voltage and current supplied to the heater in test section, respectively. The measured heat loss is less than 3\% for the single phase and subcooled flow boiling experiments in a constant environment temperature.

The subcooled flow boiling local heat transfer coefficients are calculated by the equation below: 


$$
h_{\mathrm{z}}=\frac{q}{\left(T_{\mathrm{w}, \mathrm{z}}-T_{\mathrm{f}, \mathrm{z}}\right)}
$$

where $h_{\mathrm{z}}, q, T_{\mathrm{w}, \mathrm{z}}, T_{\mathrm{f}, \mathrm{z}}$ are local heat transfer coefficient, heat flux, the temperature of silicon surface and the temperature of fluid at location $z$ in the axial direction, respectively.

The average wall superheat degree of subcooled flow boiling in the mini-gap channel is:

$$
\Delta T_{\text {sat, avg }}=T_{\mathrm{w}, \text { avg }}-T_{\text {sat, avg }}
$$

where $T_{\mathrm{w} \text {,avg }}, T_{\text {sat,avg }}$ are the arithmetic mean values of the local wall temperature and the local saturation temperature, respectively.

The fluid thermal properties involved in the calculations are based on the local or average bulk temperatures of the fluid.

\subsection{Experimental uncertainty}

Uncertainty of measured parameters and calculated parameters are shown in Table 2. Detailed calculation is in reference [17].

\section{Results and discussions}

\subsection{Subcooled boiling curve}

Fig. 6 shows the subcooled boiling curves at the six axial locations with the mass flux of $200,300,400 \mathrm{~kg} /\left(\mathrm{m}^{2} \mathrm{~s}\right)$. At relatively low heat fluxes, the temperatures at the six axial locations increase successively, performing as single-phase convection heat transfer. At larger heat fluxes, the heat transfer mode changes from the single-phase 
convection to subcooled flow boiling, with the slope of the boiling curves increasing gradually.

At the onset of nucleate boiling, no nucleate boiling hysteresis behavior was observed. On the one hand, the relatively high effective superheat in the thermal boundary layer results in easier nucleation of the bubbles [18]. On the other hand, the contact angle between deionized water and the silicon wafer is $50 \pm 3^{\circ}$, which is advantageous for bubble generation [19] compared to high-wettability fluids such as FC$72[20-22]$.

Fig. 7 shows the boiling curves based on the average superheat. When the superheat is relatively small, the heat transfer mode is single phase convection. The heat transfer coefficient increases with increased mass flux. The slope of the boiling curves increases sharply when ONB occurs, and the slope is larger for lower mass fluxes with lower superheat needed, because the fluid temperature gradient near side walls is relatively small when the flow velocity is low [18].

\subsection{Flow pattern}

High speed camera images of fluids at three heat fluxes and three mass fluxes are shown in Fig. 8. It is single phase flow at relatively low heat flux in Fig. 8 (d), (g), (h). The differences in numbers and diameters of bubbles among different conditions are demonstrated clearly. The bubble numbers are larger at the higher heat flux and the bubble diameters decrease with increased flow mass flux. There are more bubbles near the side walls, the reason of which is analyzed as follows. The heat flux is lower on the heated surface near side walls due to the high-aspect-ratio of the rectangular mini-gap channel. Thus the temperature gradient $(\nabla T=-q / k \cdot)$ near the side walls is lower. 
Because of the generally uniform circumferential temperature distribution of the heated surface, the effective superheat of the heated surface near side walls is larger, thus it is easier for bubbles to nucleate compared to those near the axis. In summary, the flow near side walls of the rectangular channel is likely retarded. Consequently, the boiling will occur more easily.

In relatively small mass flux, the size of bubbles is larger and it is harder for bubbles to depart from the surface; thus they coalesce with each other, resulting in elongated bubbly flow, as shown in Fig. 9. Then the elongated bubbly flow induces more thin film evaporation, in which transient local dryout and rewet occur frequently, as shown in Fig. 10. Red lines are the edges of dryout area and rewet area. It is interesting that bubble growth takes $12 \mathrm{~ms}$, but partial dry-out and rewetting are much slower, taking 256 ms. At smaller heat fluxes, the thin film evaporation is very effective [23] for heat transfer. The alternation between isolated bubbles and elongated bubbles is more frequent with increasing heat flux. It is noticed that Fig. 8 (b), Fig. 9 and Fig. 10 are the whole process of bubble generation, development, coalescence, partial dryout and rewetting.

\subsection{Heat transfer coefficient}

Fig. 11 (a) - (c) show the change of the local convective heat transfer coefficients at the six axial locations of the silicon wafer with increasing heat flux at mass fluxes of $200 \mathrm{~kg} /\left(\mathrm{m}^{2} \mathrm{~s}\right) .300 \mathrm{~kg} /\left(\mathrm{m}^{2} \mathrm{~s}\right)$, and $400 \mathrm{~kg} /\left(\mathrm{m}^{2} \mathrm{~s}\right)$, respectively. At relatively low heat flux $\left(q_{\mathrm{eff}}<q_{\mathrm{ONB}}\right)$, single phase heat transfer dominates the entire test section. The thickness of laminar thermal boundary layer is larger gradually along the axial direction, resulting in decreasing local heat transfer coefficient. With the increase of heat flux, the surface of the silicon wafer near exit starts boiling first, with sharply increasing heat transfer 
coefficient. For instance, the heat transfer coefficients at the three downstream locations (h4, h5, h6) of the silicon wafer increase much faster than those at the three upstream locations (h1, h2, h3) at mass flux of $300 \mathrm{~kg} /\left(\mathrm{m}^{2} \mathrm{~s}\right)$. The heat transfer coefficient of the sixth location (h6) increases 1.8 times compared to the single phase heat transfer, while the heat transfer coefficient of the first location (h1) increases 0.6 time only.

According to the classic boiling heat transfer theories, flow boiling heat transfer consists of the convective heat transfer and nucleate boiling. The convective heat transfer will be enhanced when the bubbles depart from the heated surface forming bubbly flow in the mini-gap channel. From the high-speed visualization it can be seen that the bubbles at the entrance of the silicon wafer almost nucleate and grow at the same location, while the bubble departure frequency is low. Meanwhile, more vigorous bubbly flow is formed at the downstream surface of the silicon wafer, which has a greater flow disturbance and results in stronger convective heat transfer. As the fluid subcooled degree at entrance of the silicon wafer is highest along the channel, the effect which suppresses the nucleate boiling is most prominent at entrance. Summing up the above two effects, the two-phase heat transfer coefficient at downstream of the silicon wafer is much larger than that at the entrance.

Table 3 presents four existing correlations for prediction of fully developed subcooled flow boiling heat transfer. Dittus-Boelter equation $\left(N u=0.023 \operatorname{Re}^{0.8} \operatorname{Pr}^{0.4}\right)$ is recommended to calculate single-phase heat transfer coefficient $h_{\mathrm{sp}}$ in the four correlations. However, Dittus-Boelter equation is a correlation for turbulent flow. It is noted that $h_{\mathrm{sp}}$ in the four correlations has been replaced by the laminar single phase heat transfer coefficient measured in present researches. 
Only fully developed flow boiling heat transfer data are adopted to be compared with correlations. Heat transfer of the mass flux of $200 \mathrm{~kg} /\left(\mathrm{m}^{2} \mathrm{~s}\right)$ in present experiment was not fully developed in present experiment, so only data of mass flux of $300 \mathrm{~kg} /\left(\mathrm{m}^{2} \mathrm{~s}\right)$, $400 \mathrm{~kg} /\left(\mathrm{m}^{2} \mathrm{~s}\right)$ is compared with correlations.

The predictive ability of the four methods can be seen in Fig. 12. The four correlations are all in an error band of $20 \%$ to $+25 \%$. Single phase heat transfer coefficients in four correlations are the measured results other than the equation results, and so that might be a reason of the good prediction. Chen correlation tends to have better performance at higher heat transfer coefficient.

\section{Conclusion}

In present study the flow pattern was visualized and the boiling curve, ONB, local heat transfer coefficients were analyzed with deionized water as the working fluid in a one-sided heating mini-gap channel. The fluid inlet subcooled degree was $10^{\circ} \mathrm{C}$ and the outlet temperature was lower than the saturation temperature. The mass flux was in the range of 200-400 kg/(m²), and the highest heat flux was $25 \mathrm{~W} / \mathrm{cm}^{2}$.

(1) The heat transfer mode was single phase convection at relatively low wall superheat before ONB occurred. The slope of the boiling curves increased sharply when ONB occurred, and the slope was steeper for lower mass fluxes with lower superheat needed.

(2) In vertically narrow mini-gap channel, the bubbles were generated more frequently at the higher flux and the bubble diameters decreased with increased mass flux. Elongated bubbles were also observed. The bubbles generated were larger and not 
easy to depart at lower mass fluxes, forming elongated bubbly flow and flowing upstream, leading to partial dry-out and rewetting process.

(3) The local heat transfer coefficient near the exit of the test section was larger. On one hand, the larger number of bubbles and faster bubbly flow velocity downstream made a stronger disturbance to the flow. On the other hand, relatively lower degree of subcooling downstream caused a lower reduction of the nucleate boiling heat transfer.

(4) Four existing correlations about fully developed subcooled flow boiling heat transfer coefficient are compared with present data. It is noted that single phase heat transfer coefficients recommended in correlations were replaced by experiment data. The four correlations are all in an error band of $20 \%$ to $+25 \%$. Chen correlation tends to have better performance at higher heat transfer coefficient.

\section{Acknowledgments}

This work is supported by MIT Greater China fund, National Science Foundation of Zhejiang Province, China (LZ13E060001), the National Science Foundation of China (51210011), and the Zhejiang Provincial Public Projects (analysis and test) of Zhejiang Province (No. 2015C37027). The authors are sincerely grateful to Professor Jacopo Buongiorno, Dr. Thomas J McKrell, and Ph. D. candidate Carolyn Coyle at the Department of Nuclear Science and Engineering, Massachusetts Institute of Technology for their important contribution, making the test section, productive ideas and mutual visits during the past five years. The authors thank Professor Shushen Lv in Chemical Engineering at Sun Yat-Sen University for providing the graphite sheet. 


\section{Nomenclature}

\begin{tabular}{|c|c|}
\hline Bo & Boiling number, [-] \\
\hline$c_{\mathrm{p}}$ & Specific heat capacity, $\mathrm{J} \mathrm{kg}^{-1} \mathrm{~K}^{-1}$ \\
\hline$f$ & Friction factor, [-] \\
\hline$G$ & Mass flux, $\mathrm{kg} \mathrm{m}^{-2} \mathrm{~s}^{-1}$ \\
\hline$h$ & Heat transfer coefficient, $\mathrm{W} \mathrm{m}{ }^{-2} \mathrm{~K}^{-1}$ \\
\hline$h_{\mathrm{lv}}$ & Latent heat of vaporization, $\mathrm{J} \mathrm{kg}^{-1}$ \\
\hline$I$ & Electric current, A \\
\hline$k$ & Thermal conductivity, $\mathrm{W} \mathrm{m}^{-1} \mathrm{~K}^{-1}$ \\
\hline$m$ & Mass flux, $\mathrm{kg} \mathrm{s}^{-1}$ \\
\hline $\mathrm{Nu}$ & Nusselt number, [-] \\
\hline$p$ & Pressure, Pa \\
\hline $\operatorname{Pr}$ & Prandtl number, [-] \\
\hline$q$ & Heat flux, $\mathrm{W} \mathrm{m}{ }^{-2}$ \\
\hline Q & Heat transferred, W \\
\hline $\operatorname{Re}$ & Reynolds number, [-] \\
\hline$T$ & Temperature, K \\
\hline$U$ & Electric voltage, $\mathrm{V}$ \\
\hline$x$ & Vapor quality, [-] \\
\hline \multicolumn{2}{|c|}{ Greek letters } \\
\hline$\mu$ & Dynamic viscosity, Pa s \\
\hline$\rho$ & Density, $\mathrm{kg} \mathrm{m}^{-3}$ \\
\hline$\sigma$ & Surface tension, $\mathrm{N} \mathrm{m}^{-1}$ \\
\hline
\end{tabular}




\begin{tabular}{ll} 
eff & Effective \\
in & Fluid \\
l & Flow in \\
loss & Liquid phase \\
nb & Loss \\
out & Nucleate boiling \\
sat & Flow out \\
sp & Saturation status \\
sub & Single phase \\
v & Subcooled status \\
w & Vapor phase \\
z & Wall \\
\hline
\end{tabular}




\section{References}

[1] P. Wang, P. McCluskey, A. Bar-Cohen, Two-phase liquid cooling for thermal management of IGBT power electronic module, J ELECTRON PACKAGING 135(2)(2013) 21001.

[2] D.B. Tuckerman, R. Pease, High-performance heat sinking for VLSI, Electron Device Letters, IEEE 2(5)(1981) 126-129.

[3] S.G. Kandlikar, History, Advances, and Challenges in Liquid Flow and Flow Boiling Heat Transfer in Microchannels: A Critical Review, Journal of Heat Transfer 134(3)(2012) 34001.

[4] W. Li, Z. Wu, A general correlation for evaporative heat transfer in micro/mini-channels, INT J HEAT MASS TRAN 53(9-10)(2010) 1778-1787.

[5] W. Li, Z. Wu, A general criterion for evaporative heat transfer in micro/mini-channels, INT J HEAT MASS TRAN 53(9-10)(2010) 1967-1976.

[6] W. Li, Z. Wu, A general correlation for adiabatic two-phase pressure drop in micro/mini-channels, INT J HEAT MASS TRAN 53(13-14)(2010) 2732-2739.

[7] Z. Wu, W. Li, A new predictive tool for saturated critical heat flux in micro/mini-channels: Effect of the heated length-to-diameter ratio, INT J HEAT MASS TRAN 54(13-14)(2011) 2880-2889.

[8] Z. Wu, Y. Wu, B. Sunden, W. Li, Convective vaporization in micro-fin tubes of different geometries, EXP THERM FLUID SCI 44(2013) 398-408.

[9] Z. Wu, W. Li, S. Ye, Correlations for saturated critical heat flux in microchannels, INT J HEAT MASS TRAN 54(1-3)(2011) 379-389.

[10] W. Li, Z. Wu, Generalized adiabatic pressure drop correlations in evaporative micro/minichannels, EXP THERM FLUID SCI 35(6)(2011) 866-872.

[11] T. Alam, P.S. Lee, C.R. Yap, L. Jin, A comparative study of flow boiling heat transfer and pressure drop characteristics in microgap and microchannel heat sink and an evaluation of microgap heat sink for hotspot mitigation, INT J HEAT MASS TRAN 58(1-2)(2013) 335-347.

[12] A. Bar-Cohen, J.R. Sheehan, E. Rahim, Two-phase thermal transport in microgap channelstheory, experimental results, and predictive relations, MICROGRAVITY SCI TEC 24(1)(2012) 1-15.

[13] P. Kottke, T.M. Yun, C.E. Green, Y.K. Joshi, A.G. Fedorov, Two phase convective cooling for ultra-high power dissipation in microprocessors, Thermal and Thermomechanical Phenomena in Electronic Systems (ITherm), 2014 IEEE Intersociety Conference on, IEEE, 2014, pp. 199-204.

[14] T. Alam, P.S. Lee, C.R. Yap, L. Jin, Experimental investigation of local flow boiling heat transfer and pressure drop characteristics in microgap channel, INT J MULTIPHAS FLOW 42(2012) 164-174.

[15] Y. Wang, K. Sefiane, Effects of heat flux, vapour quality, channel hydraulic diameter on flow boiling heat transfer in variable aspect ratio micro-channels using transparent heating, INT J HEAT MASS TRAN 55(9)(2012) 2235-2243.

[16] Y. Wang, K. Sefiane, S. Harmand, Flow boiling in high-aspect ratio mini-and micro-channels with FC-72 and ethanol: experimental results and heat transfer correlation assessments, EXP THERM FLUID SCI 36(2012) 93-106.

[17] K. Zhou, C. Coyle, J. Li, J. Buongiorno, W. Li, Flow boiling in vertical narrow microchannels of different surface wettability characteristics, INT J HEAT MASS TRAN 109(2017) 103-114.

[18] J.G. Collier, J.R. Thome, Convective boiling and condensation, Oxford University Press, Oxford, 1994.

[19] H.T. Phan, N. Caney, P. Marty, S. Colasson, J. Gavillet, Flow boiling of water on nanocoated surfaces in a microchannel, arXiv preprint arXiv:1008.4696 (2010).

[20] W.R. Chang, C.A. Chen, J.H. Ke, T.F. Lin, Subcooled flow boiling heat transfer and associated bubble characteristics of FC-72 on a heated micro-pin-finned silicon chip, INT J HEAT MASS TRAN 53(23-24)(2010) 5605-5621.

[21] A. Sitar, I. Sedmak, I. Golobic, Boiling of water and FC-72 in microchannels enhanced with novel features, INT J HEAT MASS TRAN 55(23-24)(2012) 6446-6457.

[22] S. Shin, G. Choi, B.S. Kim, H.H. Cho, Flow boiling heat transfer on nanowire-coated surfaces with highly wetting liquid, ENERGY 76(0)(2014) 428-435.

[23] J.R. Thome, Boiling in microchannels: a review of experiment and theory, INT J HEAT FLUID FL 25(2)(2004) 128-139. 
[24] M.M. Shah, General correlation for heat-transfer during subcooled boiling in pipes, ASHRAE JOURNAL-AMERICAN SOCIETY OF HEATING REFRIGERATING AND AIRCONDITIONING ENGINEERS, AMER SOC HEAT REFRIG AIR-CONDITIONING ENG INC 1791 TULLIE CIRCLE NE, ATLANTA, GA 30329, 1976, pp. 41-42.

[25] S.G. Kandlikar, Heat transfer characteristics in partial boiling, fully developed boiling, and significant void flow regions of subcooled flow boiling, Journal of Heat Transfer 120(2)(1998) 395401.

[26] J.C. Chen, Correlation for boiling heat transfer to saturated fluids in convective flow, Industrial \& Engineering Chemistry Process Design and Development 5(3)(1966) 322-329.

[27] Z. Liu, R.H.S. Winterton, A general correlation for saturated and subcooled flow boiling in tubes and annuli, based on a nucleate pool boiling equation, INT J HEAT MASS TRAN 34(11)(1991) 27592766. 


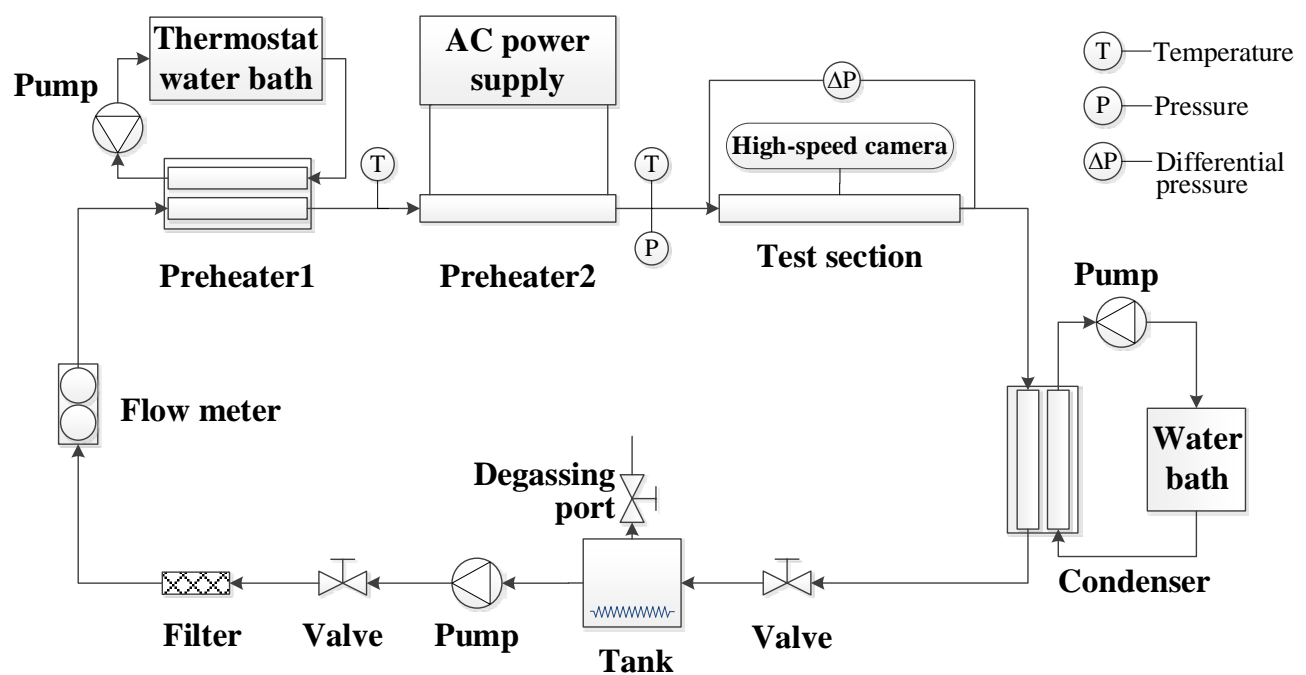

Fig. 1 Schematic of setup for flow boiling in mini-gap channel 


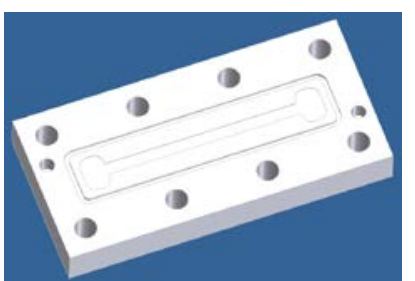

(a) top cover

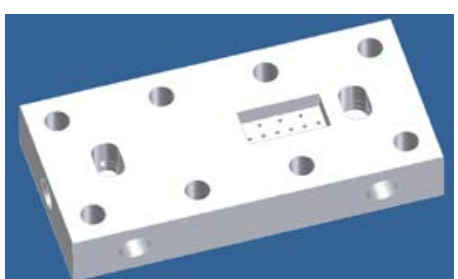

(b) bottom base

(c) Front view

Fig. 2 Cover and House for the mini-gap channel test section 


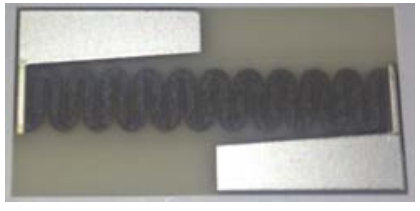

(a) Heater side

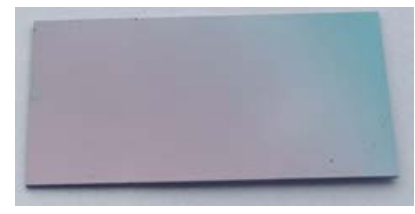

(b) Fluid side

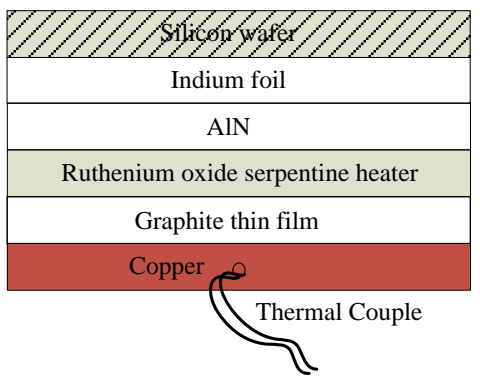

(c) Cross-section of the silicon heater Fig. 3 Silicon heater made of Ruthenium oxide serpentine heater, AlN wafer and silicon 


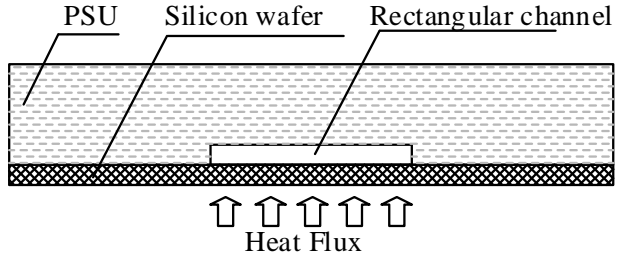

(a) top cover

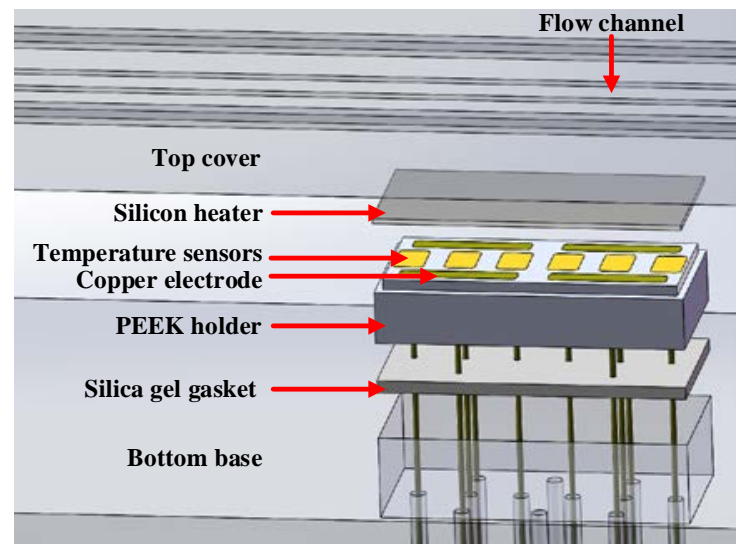

(b) test section assembly

Fig. 4 Schematic of mini-gap channel test section 


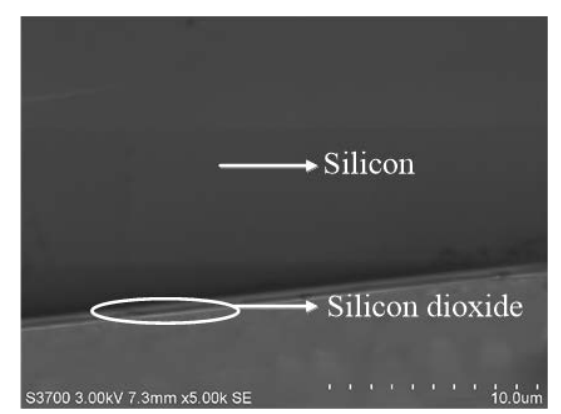

(a) SEM image of the layers

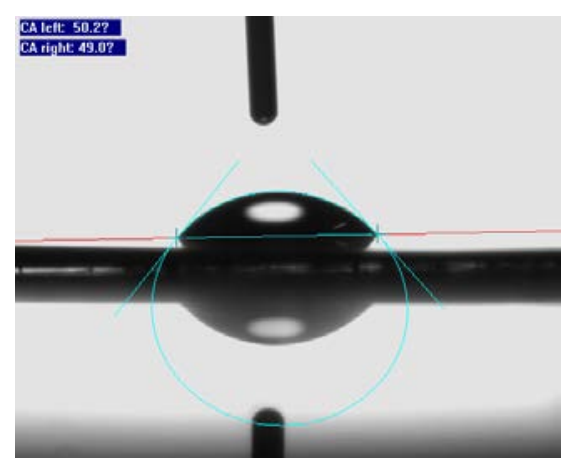

(c) Contact angle of silicon wafer oxidized

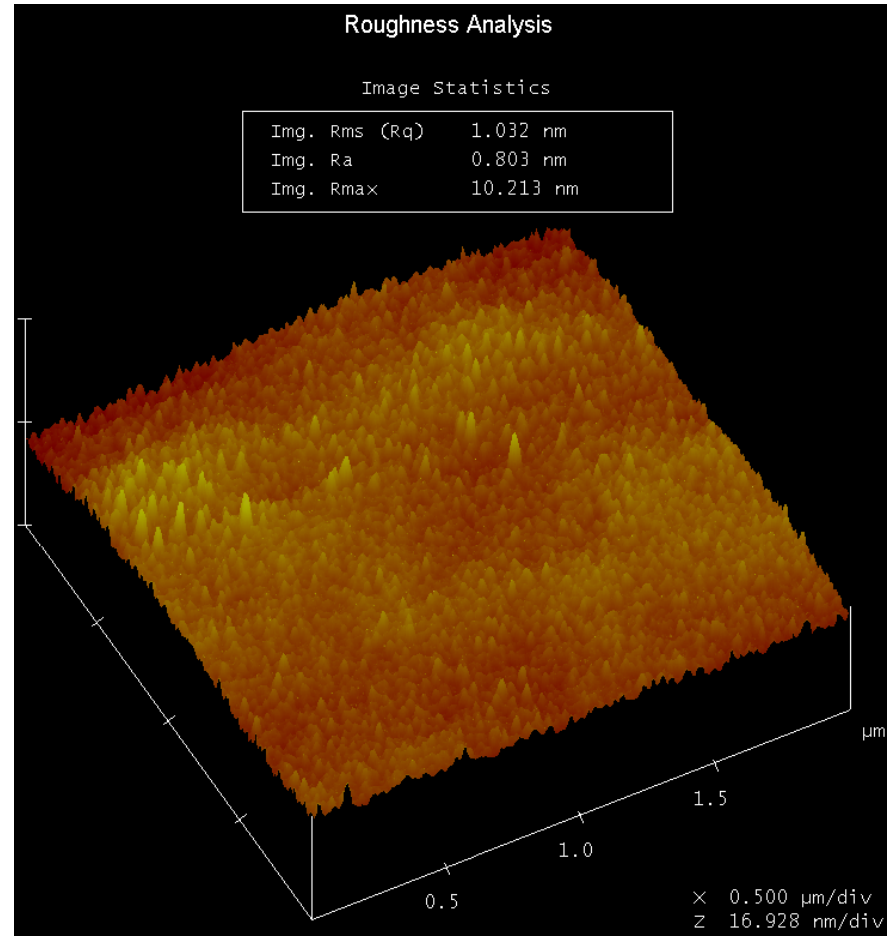

(b) AFM image of the surface

Fig. 5 SEM, AFM images and contact angle of the silicon wafer 


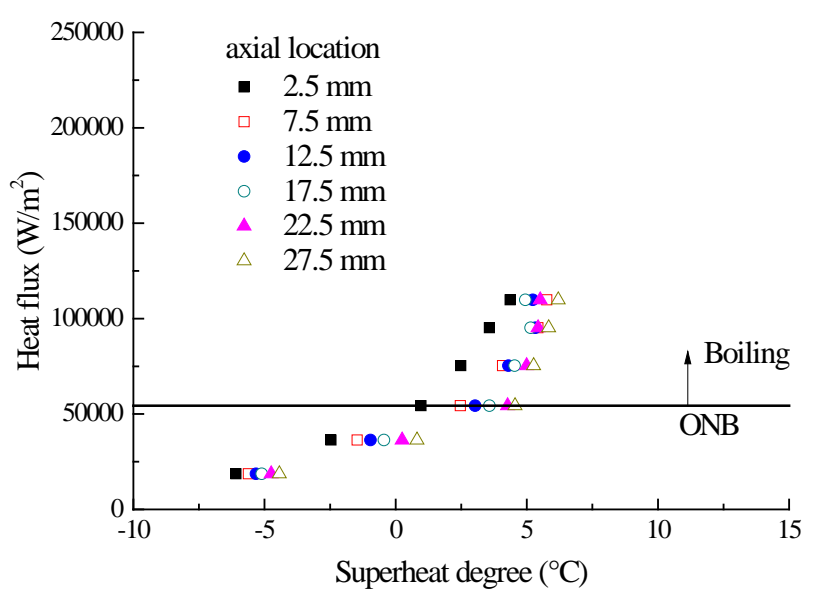

(a) $200 \mathrm{~kg} /\left(\mathrm{m}^{2} \mathrm{~s}\right)$

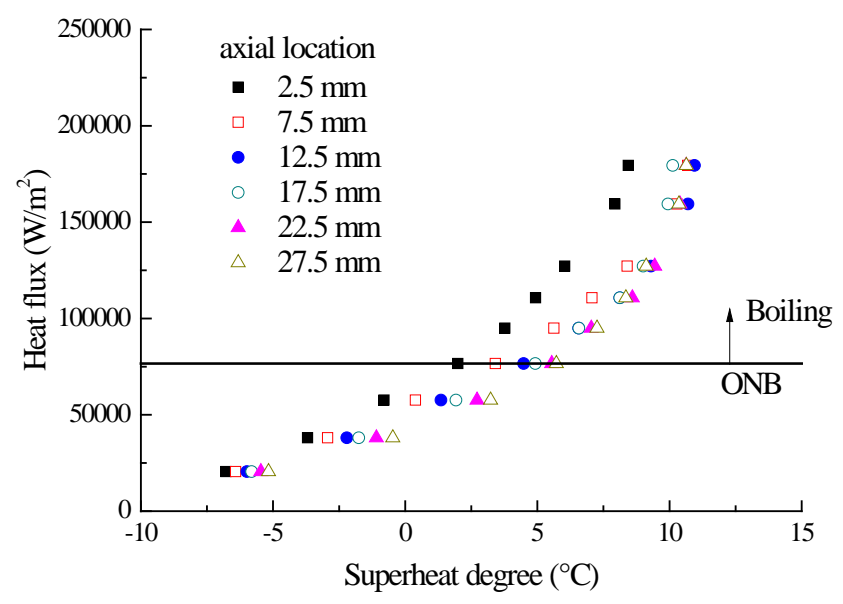

(b) $300 \mathrm{~kg} /\left(\mathrm{m}^{2} \mathrm{~s}\right)$

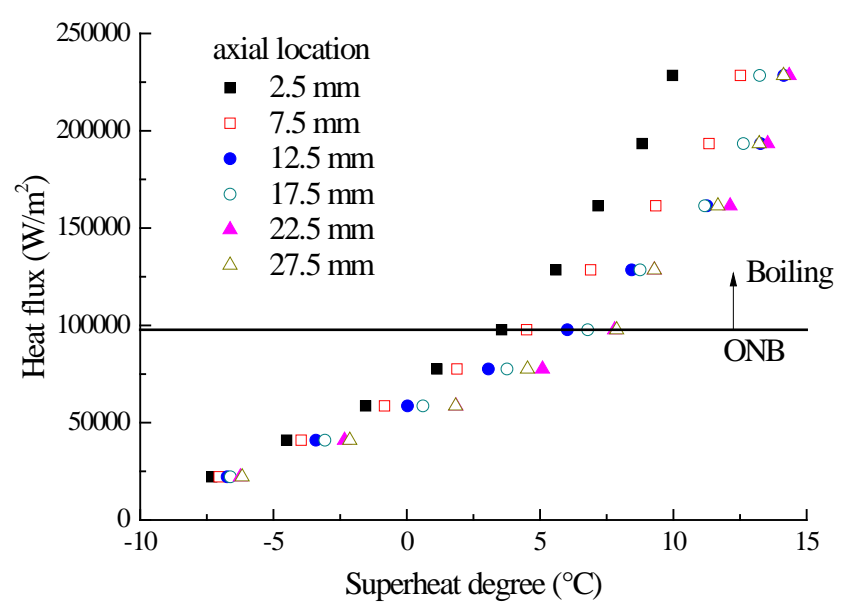

(c) $400 \mathrm{~kg} /\left(\mathrm{m}^{2} \mathrm{~s}\right)$

Fig. 6 Subcooled boiling curves at different mass fluxes 


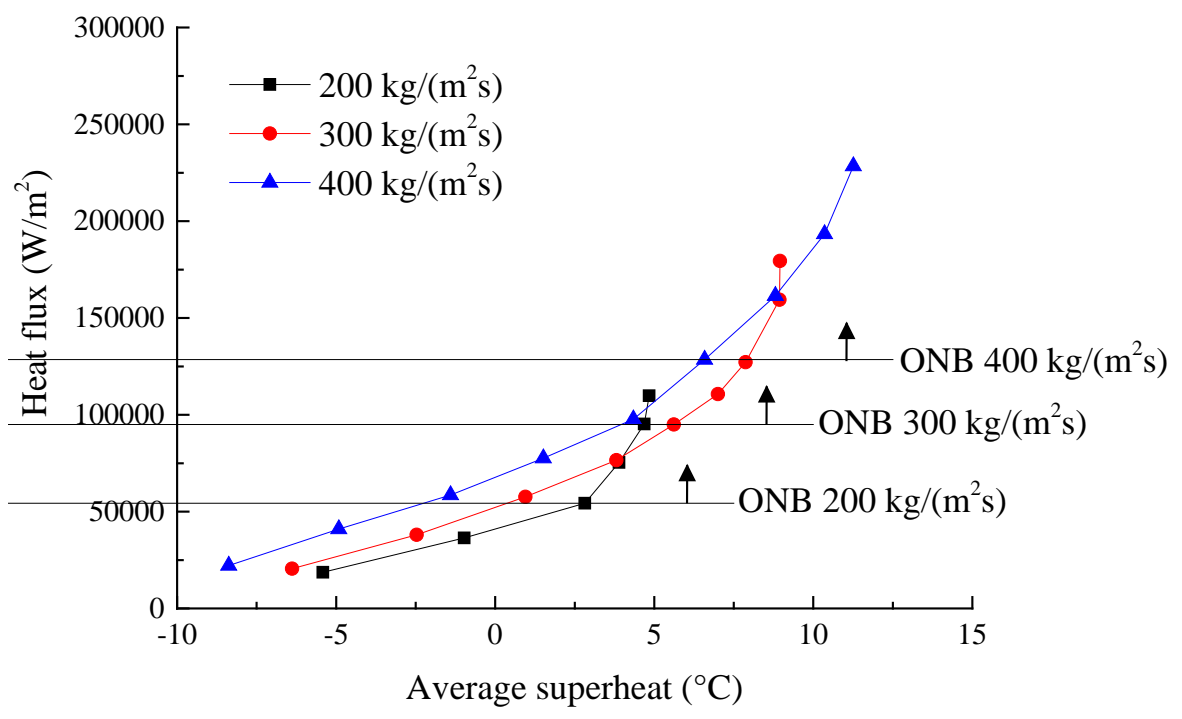

Fig. 7 Subcooled boiling curves based on average superheat 


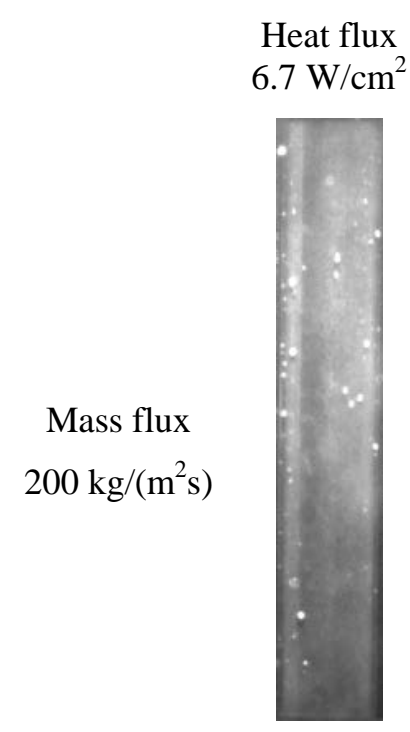

(a)

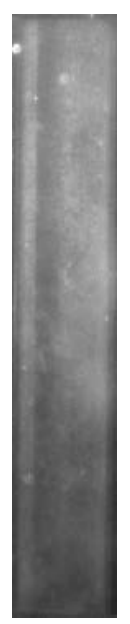

(d)

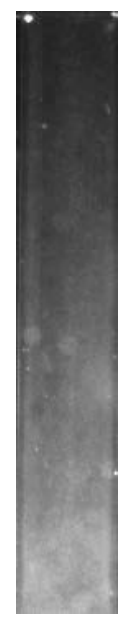

(g)

Heat flux Heat flux $10.0 \mathrm{~W} / \mathrm{cm}^{2} \quad 13.3 \mathrm{~W} / \mathrm{cm}^{2}$

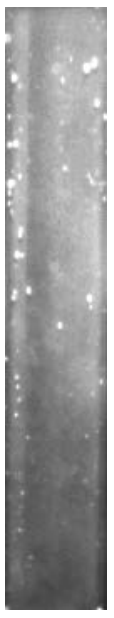

(b)

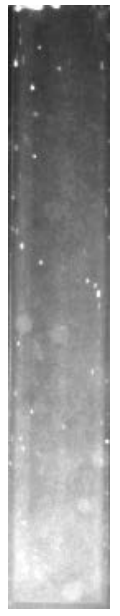

(e)

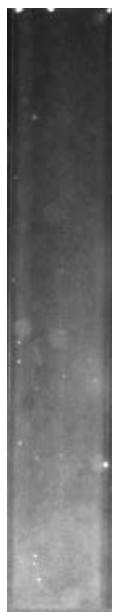

(h)

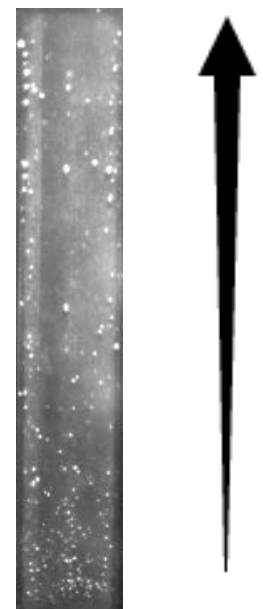

(c)
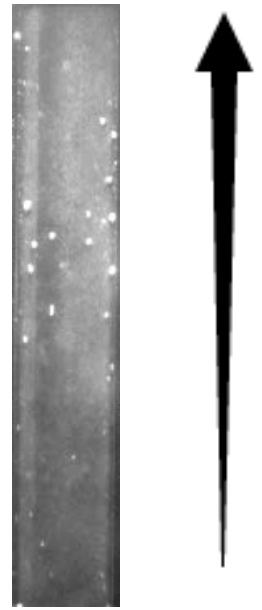

(f)
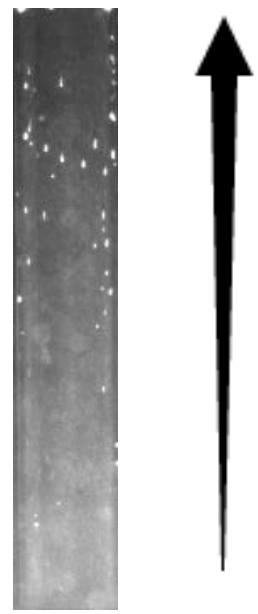

(i)

Fig. 8 Difference of bubbles in different mass flux and heat flux 


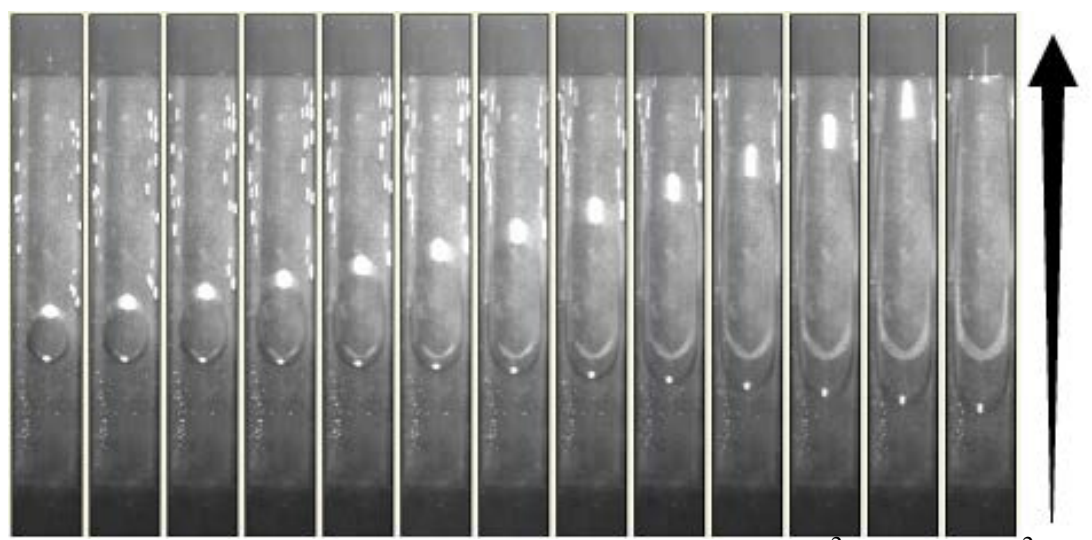

Fig. 9 The growth of single bubble to elongated bubble, $200 \mathrm{~kg} /\left(\mathrm{m}^{2} \mathrm{~s}\right), 10 \mathrm{~W} / \mathrm{cm}^{2}, 1 \mathrm{~ms}$ interval 


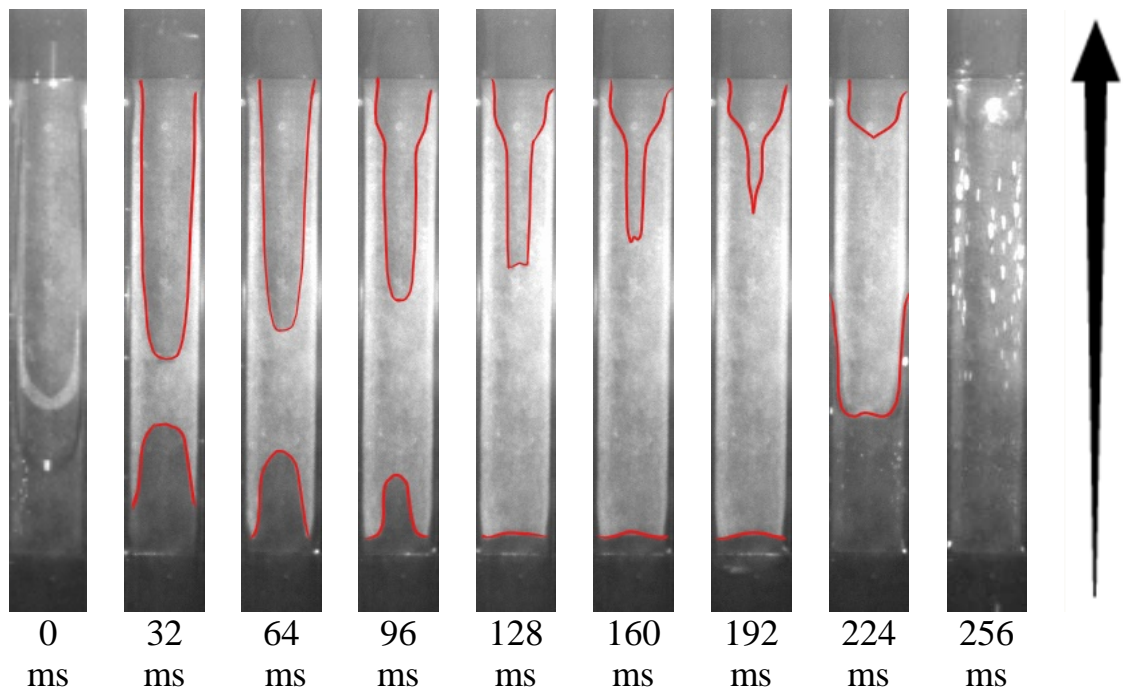

Fig. 10 Partial dry-out and rewetting process induced by elongated bubble, $200 \mathrm{~kg} /\left(\mathrm{m}^{2} \mathrm{~s}\right), 10 \mathrm{~W} / \mathrm{cm}^{2}$ 


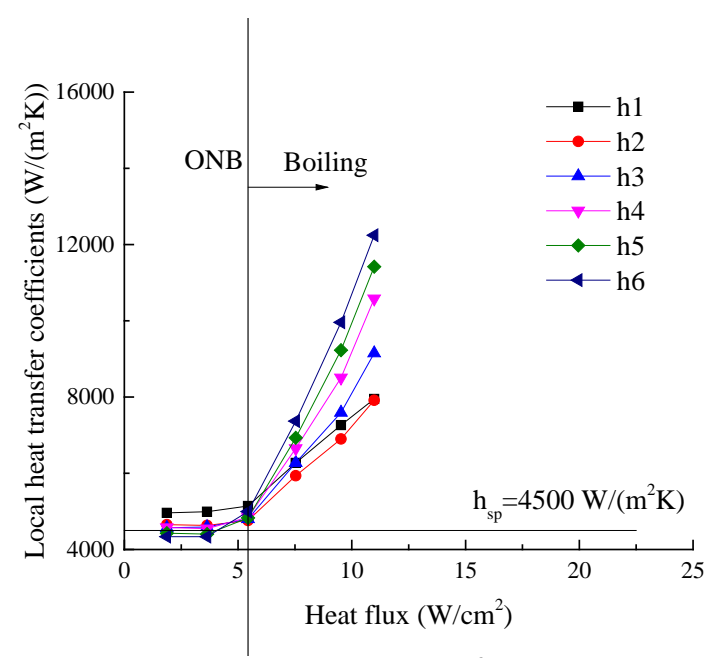

(a) $200 \mathrm{~kg} /\left(\mathrm{m}^{2} \mathrm{~s}\right)$

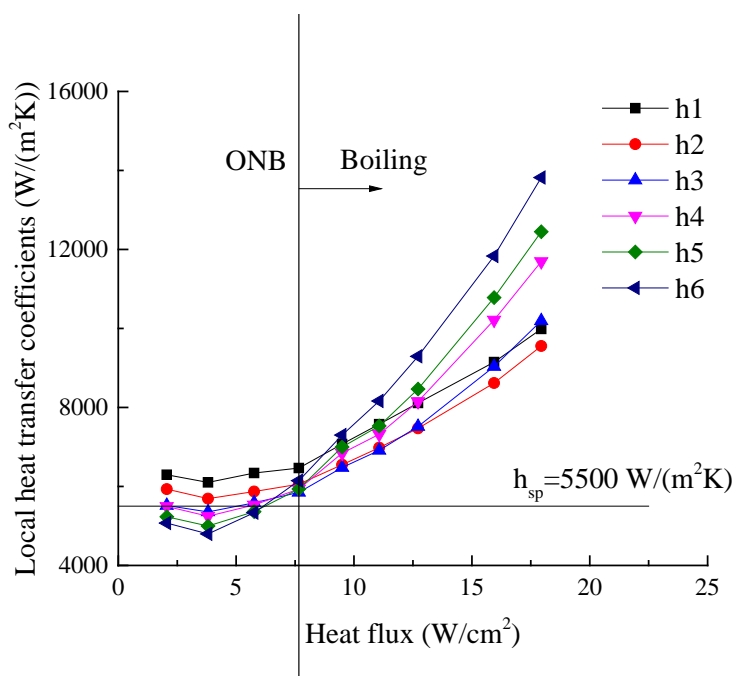

(b) $300 \mathrm{~kg} /\left(\mathrm{m}^{2} \mathrm{~s}\right)$

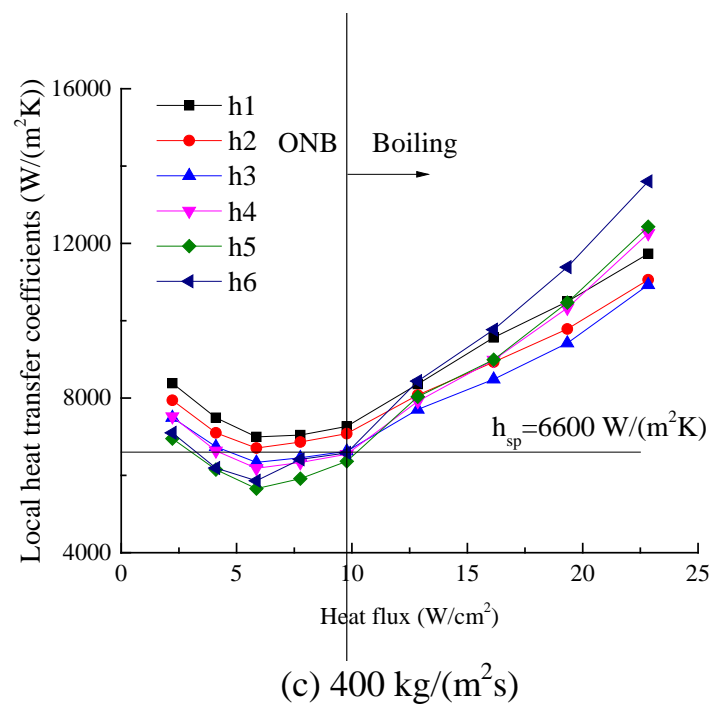

Fig. 11 The variation of local heat transfer coefficients with heat fluxes at different mass fluxes 


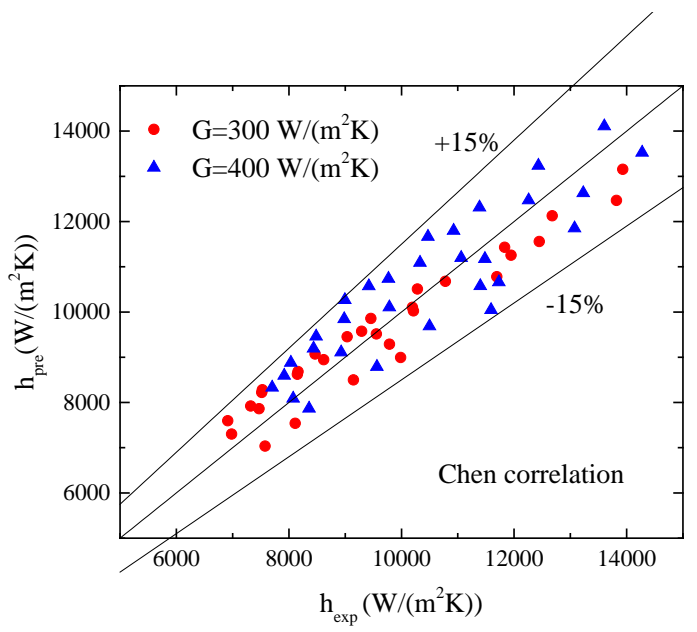

(a) Chen correlation

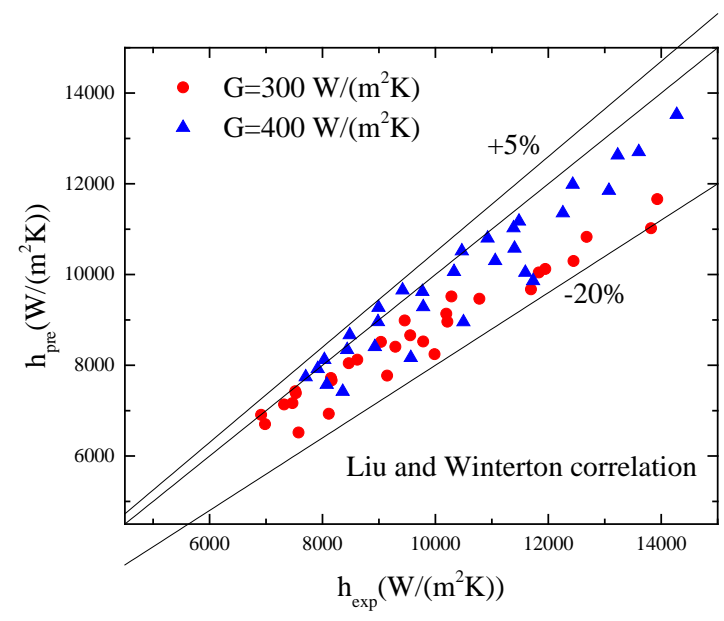

(c) Liu and Winterton correlation

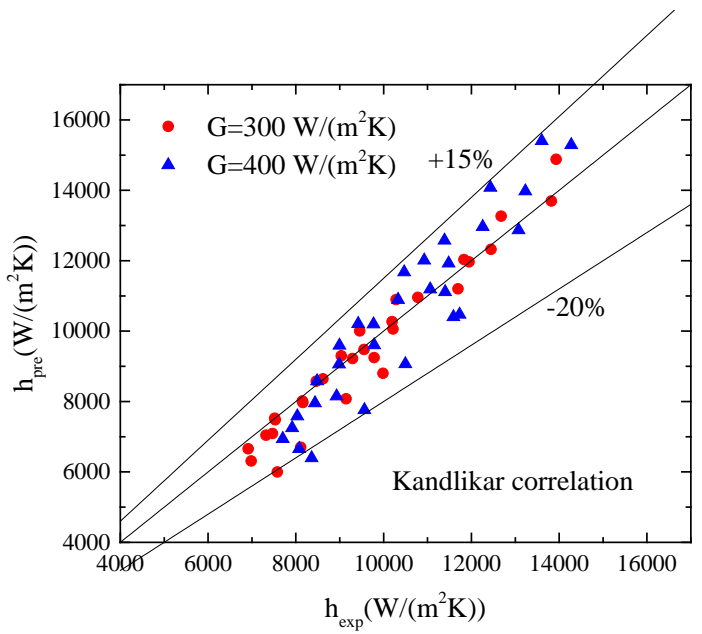

(b) Kandlikar correlation

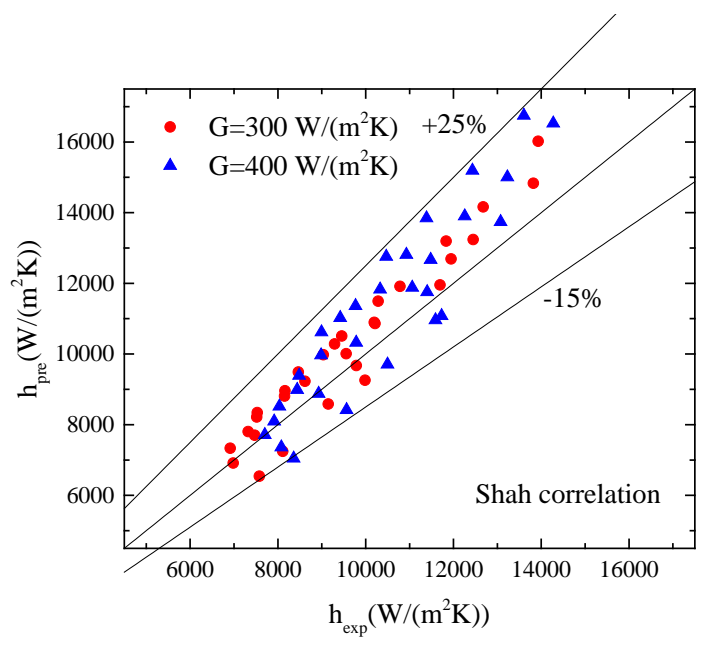

(d) Shah correlation

Fig. 12 Evaluation of the four heat-transfer correlations 
Table 1

Models of the components

\begin{tabular}{ll}
\hline Components & Models \\
\hline Data acquisition system & Agilent 34970A \\
Flow meter & Micro Motion, CMF010M \& 1700R \\
Pressure meter & YOKAGAWA, EJA110A \\
Thermocouple & OMEGA, TT-T-30 \\
High-speed camera & Phantom \\
\hline
\end{tabular}


Table 2

Uncertainty estimation for main parameters in present experiment.

\begin{tabular}{lc}
\hline Parameters & Accuracy \\
\hline Channel height and width & $\pm 0.005 \mathrm{~mm}$ \\
Test section length & $\pm 0.01 \mathrm{~mm}$ \\
Wall and fluid temperature & $\pm 0.1 \mathrm{~K}$ \\
Inlet pressure, range: 0-100 kPa & $\pm 3.75 \%$ \\
Inlet and outlet differential pressure & $\pm 1.5 \%$ \\
Mass flow rate, range: 0 -1.8 g/s & $\pm 0.3 \%$ \\
Hydraulic diameter $D_{\mathrm{h}}$, mm & $\pm 0.08 \mathrm{~mm}$ \\
Heat flux density $q$, $\mathrm{kW} \mathrm{m}^{-2}$ & $\pm 3.6 \%$ \\
Subcooled flow boiling heat transfer coefficient $h, \mathrm{~W} \mathrm{~m}^{-2} \mathrm{~K}^{-1}$ & $\pm 12.1 \%$ \\
\hline
\end{tabular}


Table 3

Description of four correlations for subcooled flow boiling heat transfer coefficient.

\begin{tabular}{|c|c|}
\hline Authors & Equations \\
\hline \multirow[t]{6}{*}{ Shah [24] } & $h=q /\left(\Delta T_{\text {sat }}+\Delta T_{\text {sub }}\right)$ \\
\hline & $\Delta T_{s a t}=q /\left(\psi h_{s p}\right)$ \\
\hline & $\psi_{0}=\left\{\psi_{0} \quad\left(\Delta T_{\text {sub }} / \Delta T_{\text {sat }} \leq 2\right)\right.$ \\
\hline & $\psi-\left\{\begin{array}{l}\psi_{0}+\Delta T_{\text {sub }} / \Delta T_{\text {sat }} \quad\left(\Delta T_{\text {sub }} / \Delta T_{\text {sat }}>2\right) \\
\text { s. }\end{array}\right.$ \\
\hline & $=\left\{1+46 B o^{0.5}\left(B o \leq 3 \times 10^{-5}\right)\right.$ \\
\hline & $\psi_{0}= \begin{cases}230 B o^{0.5} & \left(B o>3 \times 10^{-5}\right)\end{cases}$ \\
\hline \multirow[t]{4}{*}{ Kandlikar [25] } & $h=q /\left(\Delta T_{\mathrm{sat}}+\Delta T_{\mathrm{sub}}\right)$ \\
\hline & $\Delta T_{s a t}=q^{0.3} /\left[1058\left(G h_{l v}\right)^{-0.7} F_{f} h_{s p}\right]$. For water, $F_{f}=1$ \\
\hline & $(\mathrm{Re}-1000)(f / 2) \operatorname{Pr}$ \\
\hline & $1+12.7\left(\operatorname{Pr}^{2 / 3}-1\right)(f / 2)^{0.5}$ \\
\hline \multirow[t]{5}{*}{ Chen $[26]$} & $h=q /\left(\Delta T_{\text {sat }}+\Delta T_{\text {sub }}\right)=q /\left(T_{\mathrm{w}}-T_{\text {sat }}+\Delta T_{\text {sub }}\right)$ \\
\hline & $q=S h_{n b}\left(T_{w}-T_{s a t}\right)+F h_{s p}\left(T_{w}-T_{f}\right)$. For subcooled boiling, $\mathrm{F}=1$. \\
\hline & $h_{n b}=0.00122 \frac{k_{l}^{0.79} c_{p, l}^{0.45} \rho_{l}^{0.49}}{\sigma_{l}^{0.5} \mu_{l}^{0.29} h_{l v}^{0.24} \rho_{v}^{0.24}}\left(T_{w}-T_{s a t}\right)^{0.24}\left[p_{\text {sat }}\left(T_{w}\right)-p\right]^{0.75} S$ \\
\hline & $S=\frac{1}{}$ \\
\hline & $1+2.53 \times 10^{-6}\left(\left(G(1-x) D / \mu_{f}\right) F^{1.25}\right)^{1.17}$ \\
\hline \multirow[t]{7}{*}{ Liu and Winterton [27] } & $h=q /\left(\Delta T_{\mathrm{sat}}+\Delta T_{\mathrm{sub}}\right)$ \\
\hline & $q^{2}=\left[S h_{n b}\left(T_{w}-T_{s a t}\right)\right]^{2}+\left[F h_{s p}\left(T_{w}-T_{f}\right)\right]^{2}$. For subcooled boiling, $\mathrm{F}=1$ \\
\hline & $h_{n b}=55 \operatorname{Pr}^{0.12} q^{2 / 3}\left(-\log _{10} \operatorname{Pr}\right)^{-0.55} M^{-0.5}$ \\
\hline & $S=\frac{1}{1}$ \\
\hline & $1+0.055 \operatorname{Re}_{l}^{0.16}$ \\
\hline & $\begin{array}{l}\text { If the wall temperature is unknown and the heat flux is known, } \\
\text { the above equation can be transformed to: }\end{array}$ \\
\hline & $\Delta T_{\text {sat }}+\Delta T_{\text {sub }}=\frac{T_{\text {sat }}-T_{f}}{1+A_{b p}{ }^{2}}\left[1+\sqrt{\left(1+\left(1+{A_{b p}}^{2}\right)\left(A_{q p}{ }^{2}-1\right)\right)}\right]$ \\
\hline
\end{tabular}




$$
A_{b p}=\frac{F h_{s p}}{S h_{n b}}, A_{q p}=\frac{q}{S h_{n b}\left(T_{s a t}-T_{f}\right)}
$$

